\title{
GIBBERELLIN RELATIONSHIPS IN A DWARF MUTANT OF SWEET POTATO
}

\author{
HIROSHI SUGE \\ Institute for Agricultural Research, Tohoku University, Katahira, Sendai 980
}

Received January 29, 1979

\begin{abstract}
Gibberellin (GA) relationships were examined in a spontaneous dwarf mutant and its original normal variety of sweet potato. The dwarf strain had shorter internodes than the normal strain although its leaf petiole remained unchanged. Grafting of dwarf scion onto normal stock did not induce normal growth of the dwarf scion, and normal scion grafted onto dwarf stock did not alter the normal growth. The amount and kind of endogenous GAs did not seem to differ between the normal and dwarf strains. Applied $\mathrm{GA}_{3}$ markedly stimulated the growth of normal strain but did not stimulate the growth of dwarf strain markedly. Application of CCC, an inhibitor of GA biosynthesis, greatly reduced the amount of GAs and the growth of leaf petioles and stems in both strains. It was suggested that dwarf strain had a partial block to the utilization of GAs in the stem but not in the leaf petiole.
\end{abstract}

\section{INTRODUCTION}

The occurrence of dwarf mutants has long been known in crop plants. Many of these mutants had no economic value, but some of them played an important role in creating new crop varieties. Some dwarf mutants have been investigated in relation to endogenous gibberellins (GAs); maize (Phinney 1961), rice (Suge and Murakami 1968; Murakami 1972; Suge 1975, 1978; Shinbashi et al. 1975), barley (Suge 1972), wheat (Radley 1970; Fick and Qualset 1975; Gale et al. 1975a, b), bean (Proano and Green 1970; Gotoh 1970), potato (Risch 1976) and cucumber (Sandhu et al. 1972). In this paper, endogenous GA relationships are discussed in relation with the growth of a dwarf mutant of sweet potato, Ipomoea batatas.

\section{MATERIALS AND METHODS}

Plant materials: Sweet potato cv. Norin 1 (Normal strain) and its spontaneous dwarf mutant (dwart strain) were used. Although sweet potato varieties are highly heterozygous, this mutant strain may be usefull because this and its parental strain may be considered to differ in the dwarfism gene only (Fujise 1965).

The two strains were grown in the field of National Institute of Agricultural 
Sciences, Nishigahara, Kita-ku, Tokyo. Cuttings $15-20 \mathrm{~cm}$ long, obtained from the terminal tip of these plants, were planted in 1/10,000 are plastic pots, each cutting in one pot. Experiments were begun when the cuttings took roots about 6 days after planting.

Grafting experiments: Grafting experiments were conducted with the plants grown in the field. Both normal and dwarf strain were used as stock and scion. Four combinations of scion and stock, i. e., normal/normal, normal/dwarf, dwarf/dwarf and dwarf/normal. Each combination was represented by 10 graftings, and the growth of the scion was recorded about one month after grafting.

Application of chemicals: The effect of 2-chloroethyl trimethyl ammonium chloride (CCC), an inhibitor of GA biosynthesis, and that of $\mathrm{GA}_{3}$ were examined with the plants in pots. CCC was applied to the soil at the rate of one gram per pot. Two $\mu \mathrm{g}$ of $\mathrm{GA}_{3}$ in $50 \mu \mathrm{l}$ drop was applied to the apex of the dwarf strain, every other day for 20 days, a total of $20 \mu \mathrm{g}$ was applied to a plant.

In another experiments, effects of different dosages of $\mathrm{GA}_{3}$ on the two strains were examined with stem-tip cuttings. Stem tips with a length of $15 \mathrm{~cm}$ taken from the field were each placed in a $50 \mathrm{ml}$ Erlenmeyer flask and were kept in a growth cabinet kept at $25 \pm 2^{\circ} \mathrm{C}$ and 10,000 lux at the plant level. After 7 days, when adventitious roots developed different amounts of $\mathrm{GA}_{3}$ were applied to the apices of each 5 plants. Growth increment was measured 10 days after the application.

Extraction, fractionation and bioassay of endogenous GAs: Extraction, fractionation and bioassay of endogenous GAs were made as described by Suge (1975). The solvent systems used were isopropylether/acetic acid $=95: 5(\mathrm{v} / \mathrm{v})$ and isopropanol $/ 28 \%$ ammonia/ water $=10: 1: 1(\mathrm{v} / \mathrm{v} / \mathrm{v})$. Dwarf rice variety, Tan-ginbozu, was used for the bioassay.

\section{RESULTS}

The growth increments of normal and dwarf scions grafted onto normal or dwarf stocks are shown in Fig. 1, which indicates that growth rate was determined by the scion. Normal growth was not induced in dwarf scions even when they were grafted onto normal stocks, conversely the grafting of normal scions onto dwarf stocks did not alter the growth of normal scions; as shown in Fig. 2.

The effect of CCC on the normal strain and that of $\mathrm{GA}_{3}$ on the dwarf one are presented in Fig. 3. Application of $\mathrm{CCC}$ to the soil reduced stem elongation in the normal strain to the level of elongation in the dwarf strain (Figs. 3 and 4). On the other hand, exogenous application of $\mathrm{GA}_{3}$ to the apex of dwarf strain did not restore the reduced growth rate to the level of normal strain even when a total of $20 \mu \mathrm{g}$ of $\mathrm{GA}_{3}$ was used (Fig. 3).

The length of leaf petiole in the dwarf strain is almost the same as that of the normal strain although internode length was greatly shortened (Fig. 5). When, CCC was applied to soil ( $1 \mathrm{~g}$ per pot), not only the length of internode but also that of leaf petiole was greatly reduced in the normal strain. In the dwarf strain, growth retardation was more evident in leaf petiole than in internode.

The application of $\mathrm{CCC}$ reduced the level of endogenous GAs greatly (Fig. 6). 


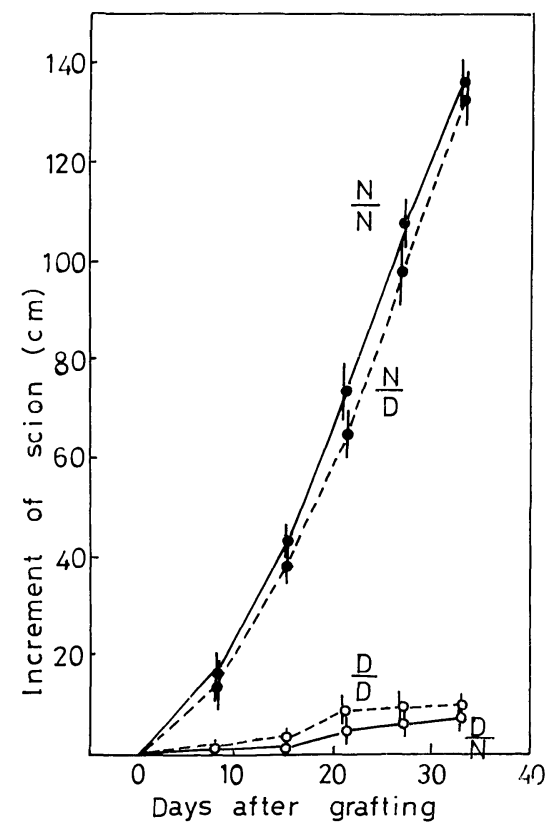

FIg. 1. Growth increment of scions in different grafting combinations. Denominator and numerator indicate stock and scion, respectively. $\mathrm{N}$ and $\mathrm{D}$ indicate normal and dwarf strain, respectively.

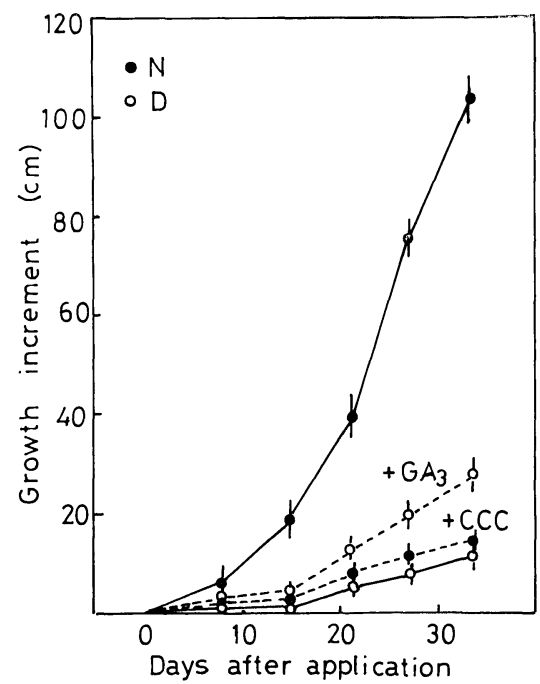

Fig. 3. Growth increments of normal and dwarf cuttings. Application of CCC to normal strain reduced the growth rate to the level of dwarf one. Application of $\mathrm{GA}_{3}$ to dwarf one did not restore the reduced growth much.

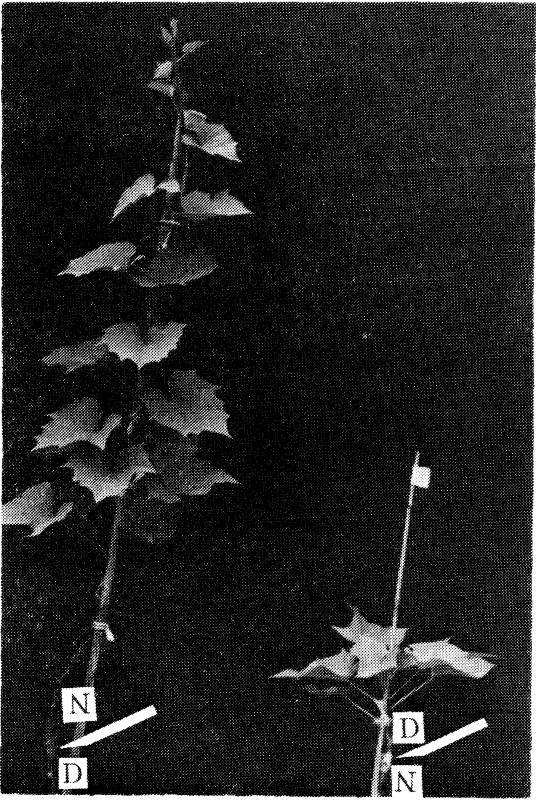

Fig. 2. Photograph showing the growth of a normal scion grafted onto a dwarf stock (left) and that of a dwarf scion onto a normal stock (right), 17 days after grafting. White arrows indicate the grafting points.

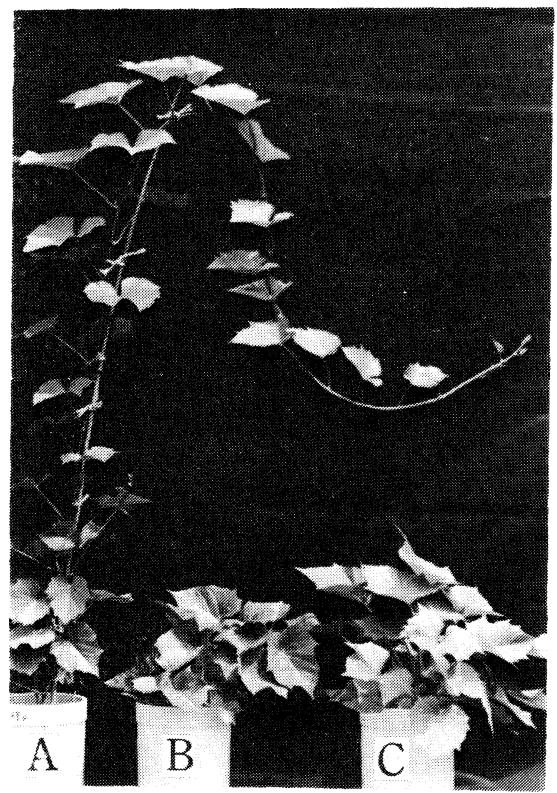

Fig. 4. Photograph showing the effect of CCC application in the growth of normal strain.

A: normal control, B: normal CCC treated, and C: dwarf control. 


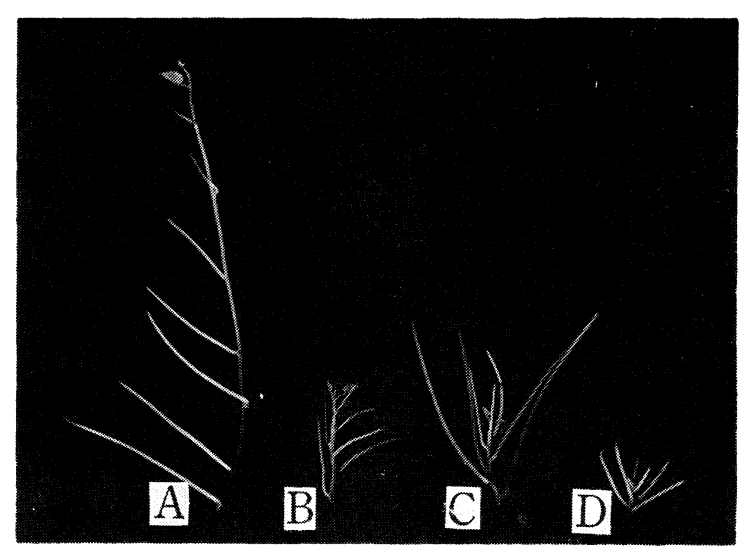

Fig. 5. Effects of CCC on the growth of leaf petioles and stems in normal and dwarf strains. A: normal control, B: normal CCC treated, C: dwarf control, and D: dwarf CCC treated. In each plant, leaf blades were removed to show petioles.

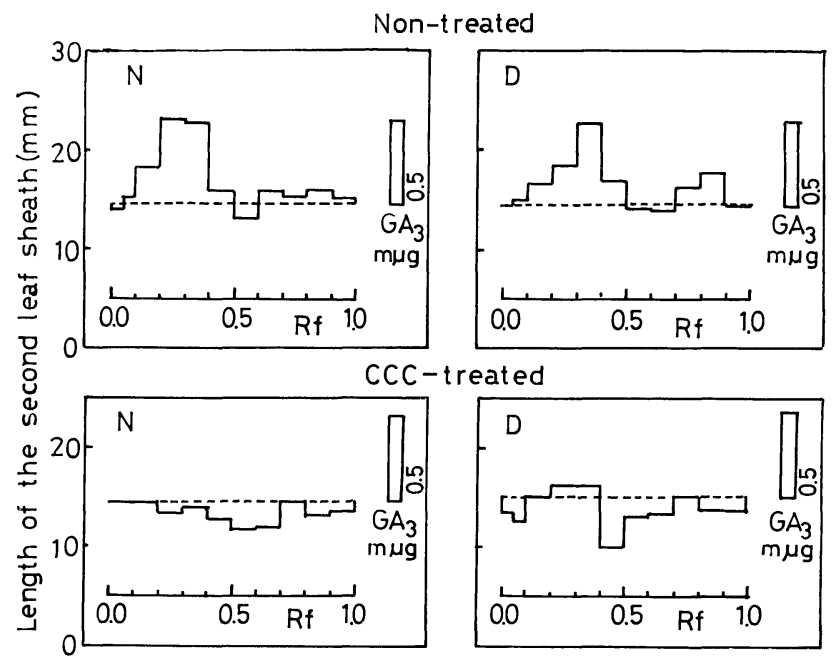

Fig. 6. Histograms showing GA activities in normal (N) and dwarf (D) strains. Isopropylether/acetic acid $=95: 5(\mathrm{v} / \mathrm{v})$ was used as the developing solvent. A dwarf rice strain "Tan-ginbozu" was used for assay.

Endogenous GA activities in both strains are also shown in Fig. 6. The figure shows that the normal and dwarf strains did not differ in endogenous GA activity. After bioassay, extracts were again grouped into two fractions; $A(\operatorname{Rf} 0.0-0.5)$ and $B(R f$ $0.5-1.0$ ), and were rechromatographed separately and developed with different solvent systems. The results of the bioassay are shown in Fig. 7. The histograms suggest that the GAs present in these two strains do not differ.

The growth response of apices to different dosage of $\mathrm{GA}_{3}$ was measured in the 
$\mathrm{N}$

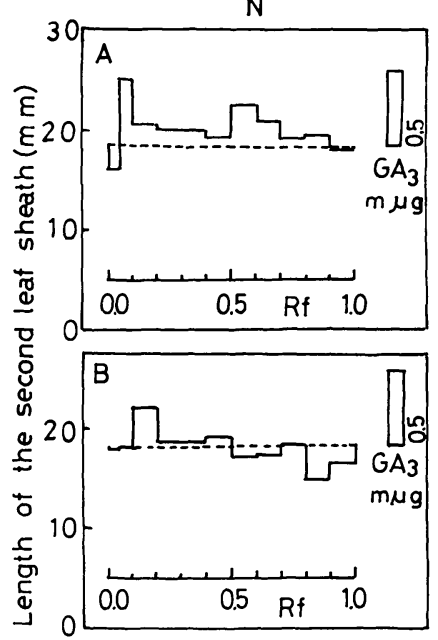

D
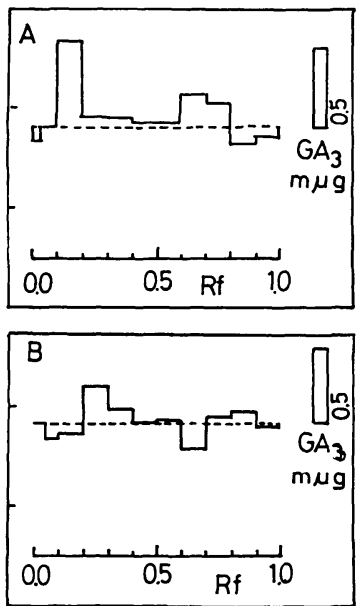

Fig. 7. Histograms showing GA activities of normal (N) and dwarf (D) strains. Fraction $\mathrm{A}$ and $\mathrm{B}$ were obtained from $\mathrm{Rf} 0.0-0.5$ and $\mathrm{Rf}$ 0.5-1.0 of the chromatograms shown in Fig. 6, respectively and rechromatographed on new thin layer plates and developed using different solvent system, isopropanol $/ 28 \%$ ammonia / water $=10: 1: 1 \quad(\mathrm{v} / \mathrm{v} / \mathrm{v})$. A dwarf rice strain "Tan-ginbozu" was used for assay.

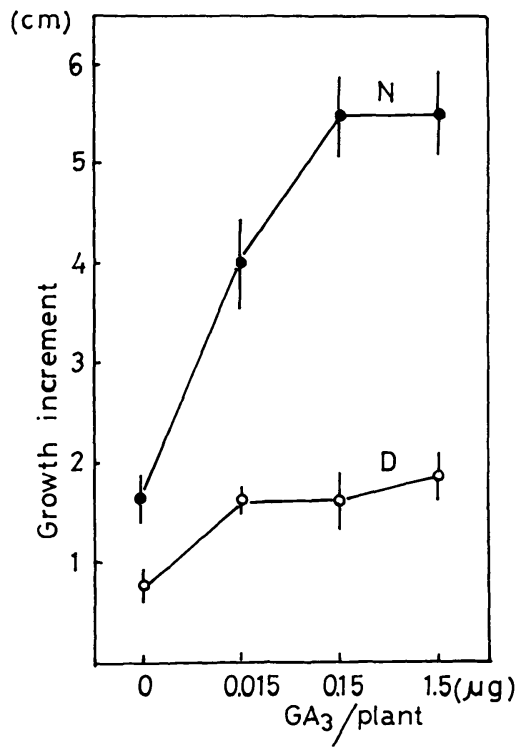

Fig. 8. Growth responses induced by different dosages of $\mathrm{GA}_{3}$ in the stem cuttings of normal $(\mathrm{N})$ and dwarf (D) strains. 
normal and dwarf strains (Fig. 8). The normal strain responded more strongly to exogenously applied $\mathrm{GA}_{3}$ than the dwarf strain.

\section{DISCUSSION}

Many dwarf mutants of crop plants were found to have smaller amount of GAs than corresponding normal strains as reported in maize (Phinney 1956), rice (Suge and Murakami 1968; Murakami 1972; Suge 1975, 1978), bean (Proano and Green 1968; Gotoh 1970), and potato (Risch 1976). The reduced growth rate of these mutants was considered to be due to genetic interruption of GA biosynthesis. However, it was also suggested the blockage in the utilization, but not in biosynthesis of GAs (Radley 1970; Fick and Qualset 1975).

The dwarf sweet potato mutant used in this experiment had shorter internodes although leaf petiole length did not differ from that of the normal strain. Grafting onto normal stocks did not induce normal growth of the dwarf scion. This suggests that the reduced growth in the dwarf strain may not be due to reduced production of GAs since hormonal substances usually moves through grafting. Phinney and Katsumi (1967) described that approach grafting between $d_{1}$ dwarf mutant and normal plant of maize induced growth response to the dwarf plant. McComb and McComb (1970) also reported that solution of $\mathrm{GA}_{3}$ poured around the roots of tall stocks carry. ing dwarf scions of pea brought about a marked increase in the rate of shoot growth demonstrating the passage of GA across the graft union. If the reduced growth rate of sweet potato was caused by interruption of GA biosynthesis, the grafting of dwarf scion onto normal stock would induce growth response of the dwarf scion. The result of the present experiment ruled out this possibility. It is also found that grafting of normal scions onto dwarf stocks did not affect the growth of scion. This suggests that the dwarf stock did not produce any inhibitory substances.

However, the extraction experiment showed that endogenous GA activities were almost the same between normal and dwarf strains and produce no evidence for the presence of an inhibitor in the dwarf strain. Therefore, the reduced growth of dwarf strain can not be attribute to genetic blockage of GA biosynthesis or production of inhibitory substance.

On the other hand, exogenous application of $\mathrm{GA}_{3}$ stimulated the growth of normal strain markedly and that of dwarf strain only slightly. An application of CCC greatly reduced GA activities in both of normal and dwarf strains. In the normal strain, this treatment greatly reduced the stem (internode) and leaf petiole length. This indicates that endogenous GAs play an important role in the growth of these organs although possibility that CCC inhibits the growth by blocking some different from GA biosynthesis cannot be eliminated; growth retardants are known to inhibit sterol synthesis (Douglas and Paleg 1974).

The results of the present experiment suggest that the dwarf strain has a partial block to the utilization of GAs in the stem, and can not utilize GAs sufficiently. However, the utilization of GAs is not blocked completely since there was no sign of accumulation of endogenous GAs and low sensitivity to exogenous $\mathrm{GA}_{3}$ was found. 
In dwarf wheat cultivars, GA utilization seems to be more completely blocked since applied $\mathrm{GA}_{3}$ did not stimulate the growth and much GAs were accumulated in the shoots (Radley 1970).

Application of CCC to the dwarf strain reduced endogenous GA level greatly and also reduced the stem growth. This suggests that endogenous GAs still work although the efficiency is greatly reduced by genetic blockage at the site of action. The growth of leaf petiole seems to differ from that of stem.

\section{ACKNOWLEDGMENTS}

The author is gratefull to Dr. Yoshio Hozyo of National Institute of Agricultural Sciences, Kitamoto, Saitama for his kind supply of sweet potato cuttings.

\section{LITERATURE CITED}

Douglas, T. J., and L. T. Paleg, 1974 Plant growth retardants as inhibitor of sterol biosynthesis in tobacco seedlings. Plant Physiol. 54: 238-245.

Fick, C. N., and C. O. Qualset, 1975 Genetic control of endosperm amylase activity and gibberellic acid response in standard-height and short-statured wheats. Proc. Natl. Acad. Sci. USA 72: 892-895.

Fujise, K. 1965 Spontaneous mutation and its use in sweet potato. In "The Use of Spontaneous Mutation in Plant Breeding" Gamma Field Symposia No. 4. pp. 43-53.

Gale, M. D., C. N. Law, G. A. Marshall, and A. J. Wordland, 1975 The genetic control of gibberellic acid insensitivity and coleoptile length in a "dwarf" wheat. Heredity 34: 392-399.

Gale, M. D., and G. A. Marshall, 1975 The nature and genetic control of gibberellin insensitivity in dwarf wheat grain. Heredity 35: 55-65.

Gotoh, N., 1970 A comparison of gibberellin-like substance in germinating cotyledons of tall and dwarf varieties of Phaseolus vulgaris L. Plant and Cell Physiol. 11: 355-359.

McComb, A. J., and J. A. McComb, 1970 Growth substances and the relation between phenotype and genotype in Pisum sativum. Planta 91: 235-245.

Murakami, Y., 1972 Dwarfing genes in rice and their relation to the gibberellin biosynthesis. In "Plant Growth Substances 1970" (D. C. Carr, ed.) pp. 167-174. Springer-Verlag, Berlin.

Phinney, B. O., 1961 Dwarfing genes in Zea mays and their relation to the gibberellins. In "Plant Growth Regulation" (R. M. Klein, ed.) pp. 489-501. Iowa State Coll. Press, Ames Iowa.

Phinney, B. O., and M. Katsumi, 1967 Genetic control of gibberellin production. Chemical Regulation of Plants 2: 79-83 (in Japanese).

Proano, N. A., and G.L. Green, 1968 Endogenous gibberellins of a radiation induced single gene mutant of bean. Plant Physiol. 43: 613-618.

Radley, M., 1970 Comparison of endogenous gibberellins and response to applied gibberellin of some dwarf and tall wheat cultivars. Planta 92: 292-300.

Risch, H., 1976 Untersuchungen über den endogenen Gibberellin-Gehalt an hoch- und niedrigwachsenden Kartoffelsorten. Biochem. Physiol. Pflanzen 170: 67-75.

Sandhu, M. S., R. G. Lockard, C. Grunwald, and L. P. Stoltz, 1972 Endogenous growth regulators in dwarf and tall cucumber. J. Amer. Soc. Hort. Sci. 97: 387-389.

Shinbashi, N., T. Kinoshita, and M. Takahashi, 1975 Gibberellin metabolism affected by the causal genes for 'Hosetsu-dwarf' and 'Tan-ginbozu-dwarf'. Genetic studies on rice plant LXIII. Memoirs Fac. Agric. Hokkaido Univ. 9: 201-207 (in Japanese).

Suge, H., 1972 Effect of $u z u(u z)$ gene on the level of endogenous gibberellins in barley. Japan. 
J. Genetics 47: 423-430.

Suge, H., 1975 Complementary genes for height inheritance in relation to gibberellin production in rice plants. Japan. J. Genetics 50: 121-131.

Suge, H., 1978 The genetic control of gibberellin production in rice. Japan, J. Genetics 53: 199-207.

Suge, H., and Y. Murakami, 1968 Occurrence of a rice mutant deficient in gibberellin-like substances. Plant and Cell Physiol. 9: 411-414. 